\section{Importância das Peregrinações para o Turismo Mundial}

\section{Glauber Eduardo de Oliveira Santos ${ }^{1}$}

RESUMO: Disserta a respeito das peregrinaçōes como fenômeno, enfocando os aspectos históricos e atuais. Analisa a importância do ato de peregrinar, em meio a novos paradigmas, como atividade turística. Também aponta os principais centros de peregrinação no mundo.

PALAVRAS-CHAVE: turismo religioso, peregrinação, romaria, história do turismo.

ABSTRACT: Thispaperpresentsapilgrimage as atouristic phenomenon, emphasizing historical and current aspects, analysing its importance through new touristic activities models. It also points out the main pilgrimage centers in the world.

KEYWORDS: pilgrimage, religious tourism, tourism history.

\section{Introdução}

As peregrinações foram e ainda são um fenômeno de grande expressão. No passado, tiveram grande influência no desenvol vimento histórico de todos os povos. As peregrinações propiciaram o encontro de inúmeras culturas, a realização de diversas guerras, o surgimento de grandes cidades, etc.

Para o turismo sua importância baseia-se em dois aspectos: histórico e atual. Historicamente, as peregrinações formaram, juntamente com os destinos balneários, os primórdios do turismo. Atualmente, sua relevância deve-se à dimensão do fenômeno. Existem vários milhões de pessoas que se deslocam todos os anos $\mathrm{cm}$ direção a locais sagrados.

1. Aluno do curso de turismo da Escola de Comunicaçōes e Artes da Universidade de São Paulo (ECA/USP) End.: R. José Cândido Freire, 219 - Parque São Domingos - São Paulo - SP - Brasil Tel: (11) 3831-8117. E-mail: glaubereduardo@ hotmail.com
Mas apesar da enorme expressão, as peregrinações carecem de estudos. Existem pouquíssimos trabalhos que procuram descrever e analisar o fenômeno, dos quais um número ainda menor liga-o ao turismo.

Deste modo, a intenção deste artigo não é dissecar o assunto, mas chamar a atenção para sua importância. Um movimento tão grande de pessoas, ou turistas, não pode passar despercebido. Com base em pesquisas (livros, revistas, guias e Internet) este artigo pretende dissertar a respeito das origens históricas e de aspectos atuais do fenômeno no Brasil e no mundo.

\section{Origem}

O termo peregrinar vem do latim pere rinare e significa ir a lugares santos ou de devoção com o objetivo de venerar o lugar visitado, pedir por ajuda ou cumprir obrigações religiosas.

A história deste fenômeno é muito antiga e se confunde com a própria história das crenças e religiões. Em tempos remotos, era comum a crença em divindades locais. Os seres divinos tinham poderes apenas sobre certas forças ou locais. Sendo assim, os deuses das montanhas não tinham poderes sobre as planícies e vice-versa. Quando uma pessoa pertencente a uma tribo das montanhas encontrava-se longe de seu local de origem e necessitava de ajuda divina, esta peregrinava de volta às montanhas para pedir a seu Deus. Foi assim que, a partir das crenças dos homens primitivos, originaram-se as peregrinações (Jarret, 2000).

Em virtude de sua história tão profundamente ligada à evolução, o ato de peregrinar é considerado por muitos intrínseco à natureza humana. É também encontrado em todas as religiões. Os egípcios peregrinavam ao Oráculo de Amon, em Tebas; os gregos ao Oráculo de Apollo, em Delfos; ao Templo de Ártemis (uma das sete maravilhas do mundo antigo), em Éfeso; ao templo de Pallas Atena, em Atenas; ou ao Templo de Zeus, em Olímpia; os astecas à Quetzalcôatl; os incas a cidade de Cuzco e ao lago Titicaca.

Mas foi com o surgimento das religiões monoteístas que as peregrinações tiveram grande impulso. Aumentaram enormemente em número e mudaram-se os objetivos. Agora, tinham o interesse de visitar e venerar os locais ligados ao nascimento, vida e morte dos respectivos deuses e profetas (Jarret, 2000).

No cristianismo, esta expressão obteve seu ápice com o surgimento de milhares de santos, que por sua vez formaram novos centros de peregrinações. Outro fator que contribuiu para a popularização destas jornadas foi a ligação feita pela igreja católica entre peregrinação e penitência. Muitos peregrinos começaram a entender esta como um meio de salvação de seus pecados.

Durante a Idade Média, as peregrinações tiveram grande importância na Europa. Em nome delas, inúmeras estradas foram abertas, muitos hospitais (que na época eram um misto de hotel e casa de saúde) foram construídos, e até guerras foram realizadas. As cruzadas talvez tenham sido as realizações mais notáveis que, a 
princípio, foram feitas em favor das peregrinações. Exerceram também uma grande influência cultural, colocando em contato diferentes povos. Logo, as peregrinações foram, durante este período, um dos fenômenos mais dinâmicos e influcntes (Roussel, 1956).

Porém, no final da Idade Média, as peregrinações começaram a tornar-se alvo de especulação e corrupção, bem como todo o corpo eclesiástico. A Reforma também teve sua taxa de contribuição para a decadência desta expressão no mundo cristão. O número de pessoas a realizarem peregrinações caiu sensivelmente em toda a Europa. Este conjunto de mudanças no plano religioso, aliado a outras nos planos político, econômico, social e cultural, fez com que as peregrinações perdessem o papel de grande relevância na formação do mund• ocidental.

Com o advento dos meios de transporte modernos as peregrinações sofreram uma drástica diminuição em sua duração. Com isso, voltaram a crescer em número, sem recuperar, porém, a expressão de outrora.

\section{Peregrinaçōes no Mundo Atual}

Hoje, apesar da relativa perda de expressão que o fenômeno sofreu, principalmente no cristianismo, as percgrinações ainda movimentam milhões de pessoas por ano em todo o mundo. É um importante fluxo de turistas que, em muitos casos, vem conhecendo surpreendentes crescimentos. Esta significativa expressão não se restringe ao mundo cristão. Os peregrinos partem de todos os cantos do globo, levando as mais diferentes crenças aos mais diversos destinos. Peregrinar continua sendo um fenômeno comum a todas as religiões.

Porém, esta atividade encontra-se em meio a novos paradigmas. As mudanças culturais, sociais, tecnológicas e políticas que marcaram os últimos séculos provocaram diversas alterações. O enfraquecimento de valores religiosos, como o da veneração de locais sagrados e da penitência, principalmente no mundo cristão, tornou o ato de peregrinar bem menos popular e importante. O crescimento da tolerância de ordem religiosa, étnica e política, aliado ao fortalecimento das relações diplomáticas entre países, deu à peregrinação um certo grau de segurança. O surgimento de facilidade de serviços, como hospedagem, alimentação, informação e principalmente transportes, também contribuiu positivamente.

Existem no mundo milhares de centros de peregrinação, que estão ligados a dezenas de diferentes religiões. Não caberia aqui citar cada um deles. Porém é de interesse que se aponte as principais.

Meca é hoje centro de atração de cerca de dois milhões de peregrinos a cada hajj, ou período de peregrinação. Segundo o Islã, um muçulmano deve ir a Meca pelo menos uma vez na vida e este é o principal fator que faz da cidade o maior centro de atração de peregrinos do mundo. O fenômeno tomou proporções tão gigantescas que o governo saudita teve que tomar medidas restritivas. Os países muçulmanos podem mandar apenas $0,1 \%$ da população à Meca a cada hajj. Até mesmo os sauditas tiveram seus direitos restringidos: podem peregrinar apenas uma vez a cada cinco anos. Para receber os peregrinos, são montadas verdadeiras cidades de tendas ao redor de Meca. O aeroporto de Jida transforma-se no mais movimentado do mundo neste período. Até mesmo satélites são utilizados para controlar o deslocamento das multidões ao redor da Caaba (pedra negra que simboliza a moradia de Alá). (Romanini, 1998).

Jerusalém é considerada cidade sagrada pelas três religiões "filhas" de Abraão: cristianismo, judaísmo e islamismo. Hoje é palco de disputas entre judeus e palestinos. Apesar das tenções políticas e militares, Jerusalém recebe anualmente milhões de peregrinos que vão reverenciar seus inúmeros templos, ruas e locais sagrados. O fluxo turístico do local possui características interessantes. Em períodos de maiores tensōes, o número de turistas diminui com uma rapidez única e, ao contrário, em períodos de maior segurança, o fluxo conhece um dos mais rápidos crescimentos do mundo.

Roma é a capital do catolicismo, a cidade eterna. É uma das cidades mais visitadas do mundo, porém grande parte dos visitantes possui motivações não religiosas. Apesar disso, o turismo religioso em Roma possui grande importância. Como não poderia deixar de ser, uma vez que a cidade é um dos pilares do cristianismo, milhares de pessoas visitam a cidade anualmente movidos pela fé (Fuster, 1985).

Santiago de Compostela ć o destino de uma das peregrinações mais interessantes. Sua história iniciou-se no século IX, quando, segundo a lenda, um camponês viu uma chuva de estrelas tocar o chão (Compostela significa campo de estrelas) em algum lugar da Galícia, na atual Espanha. Naquele momento foi revelado o exato local onde no ano de 44 d.C. foi enterrado o corpo do apóstolo Tiago. A partir deste momento começaram a surgir inúmeros peregrinos que atravessavam todo o Norte da Espanha para rezar e pedir perdão ao apóstolo. A peregrinação teve grande influência na formação da Espanha, sendo usada como ferramenta de ligação do território. Ao fim da Idade Média ou meados da Idade Moderna o fenômeno caiu em um forte processo de enfraquecimento. No início dos anos de 1980, segundo Herrera (1984), o caminho enfrentava um quase total descaso das autoridades e da sociedade espanhola como um todo. Esse quadro começou a alterar-se no final da década de 80 , quando o governo espanhol percebeu o grande potencial do caminho e passou a investir milhões de dólares em infra-estrutura e publicidade. Em 1999, após um rápido processo de ressurgimento, o Caminho de Santiago recebeu mais de $150 \mathrm{mil}$ peregrinos que atingiram a cidade a pé, de bicicleta ou a cavalo. A esse número somase ainda outro muito grande de peregrinos que visitaram a cidade de carro, avião, trem etc. Santiago é hoje, novamente, uma cidade de peregrinação em evidência no contexto mundial. Destaca-se ainda a presença de brasileiros que também, em 1999, superaram a marca dos dois mil, apesar da larga distância entre os dois países.

Varanasi ou Bernares é a principal cidade sagrada do hinduísmo. Segundo a tradição, os hindus devem pelo menos uma vez na vida ir até o local para tomar banho no rio Ganges. Apesar do grande nível de poluição do rio, o ritual é tido como um dos passos para atingir o nirvana ou paraíso. Existem na cidade dezenas de ghats, 
escadarias próprias para o banho. Em um deles, o de Manikarnika,é realizado o ritual de cremação e despejo das cinzas dos hindus que possuem condições fïnanceiras para tal. Os que não possuem atiram os cadáveres inteiros dentro do rio (Ribeiro, 1997).

Outras grandes peregrinações podem ser citadas comoFátima, em Portugual, Montserrat, Zaragoza e Ujuć; na Espanha, Lourdes, Le Puy e Chartres; na França Assis e Pádua; na Itália, Canterbury; na Inglaterra, Kashi; na Índia, Shri Pada; em Sri Lanka, Lhassa; no Tibet, Ise; e Shikoku no Japão, e ainda Tepeyac no México.

\section{Peregrinação no Brasil}

Desde sua origem o Brasil esteve intimamente ligado à religião. Além de ser o maior país católico do mundo, o Brasil possui ainda diversas outras crenças o religiões, principalmente de origem africana, protestante e asiática.

E como qualquer outro país do mundo, o Brasil possui considerável atividade turística ligada às peregrinações. São milhões de pessoas que se deslocam todos os anos. Não cxistem estatísticas confiáveis c atuais a respeito, porém obviamente tratase de um movimento turístico de enorme potencial, merecendo a atenção dos órgãos públicos e da iniciativa privada.

Um aspecto relativo às peregrinações no Brasil a ser destacado é o fenômeno populardas romarias coletivas. Romaria, que deriva da palavra Roma, originalmente designava as peregrinações feitas somente a csta cidade. Posteriormentc passou a designar toda e qualquerperegrinação. Quando coletivas, as romarias possuem, além do objetivo de visitação do destino, um caráter social, tornando-sc quase uma festa. Uma das maiores, senão a maior concentração de romarias do Brasil, encontra-se no Estado de São Paulo, onde existem pelo menos 46 municípios emissores de romarias (Macedo, 1999).

São Paulo possui também o maior número de centros de peregrinação do Brasil (Macedo, 1999), em que o principal é obviamente a cidade de Aparecida. A história religiosa do local começou, segundo informações do site oficial da cidade, em 1717, quando a imagem de Nossa Senhora da Conceição foi encontrada nas águas do Rio Paraíba do Sul. A partir daí, uma longa série de milagres foram relatados e inúmeras romarias começaram a surgir. Hoje a cidade tornou-se um dos maiores centros turísticos do país, com cerca de 7 milhões de visitantes por ano, 200 mil apenas no dia 12 de outubro, dia de Nossa Senhora Aparecida. Ressalta-se que a população local é de apenas 34 mil habitantes. Para atenderessa demanda, Aparecida possui uma estrutura grandiosa. A basílica de Aparecida é a segunda maior igreja católica do mundo, com $173 \mathrm{~m}$ de comprimento, $168 \mathrm{~m}$ de largura c capacidade para 45 mil pessoas. Os $272 \mathrm{mil} \mathrm{m}^{2}$ de estacionamento comportam 4 mil ônibus e 6 mil carros. Existe ainda uma completa, porćm insuficiente infra-estrutura de apoio com sanitários, ambulatórios, refeitório, berçário, estação de rádio e centenas de lojas.
Menor que Aparecida, porém ainda com grande importância, está a cidade de Pirapora do Bom Jesus, também no Estado de São Paulo. Esta recebe anualmente dezenas de romarias vindas das cidades da região. A imagem do Bom Jesus, assim como a de Nossa Senhora Aparecida, foi encontrada num rio, porém oito anos mais tarde que a primeira.

Outra imagem do Bom Jesus de grande importânciaé a de Iguape. Diz a lenda que, a partir da Juréia, a imagem deveria ter sido levada no sentido de Peruíbe. Porém a cada tentativa a imagem ganhava mais peso, tornando seu transporte impossível Quando a tentativa tomou sentido contrário, a imagem "milacurosamente" perdeu peso, chegando a Iguape, onde permanece até hoje. Diversas romarias vão à cidade para reverenciar a imagem, tornando a festa do Bom Jesus o maior acontecimento rcligioso da região do vale do Ribeira.

Existem ainda no Estado pelo menos mais dezoito destinos de peregrinação, destacando-se a Santa Cabeça, cm Mairiporã, o Santuário do Bom Jesus, em Bom Jesus dos Perdõcs, o túmulo do frei Galvão e a Igreja da Penha e mais quatro cemitérios na cidade de São Paulo.

Fora do Estado de São Paulo, destacam-se Juazeiro do Nortc, no Ceará e Bom Jesus da Lapa, na Bahia. O primeiro é um já consagrado destino de fiéis e scguidores do padre Cícero Romão, o Padrinho, que recebe cerca de 100 mil romeiros para a festa do final de outubro. O segundo é também destino de milhares de romeiros que vão à cidade para ver e rezar nas grutas de Nossa Senhora da Soledade e de Santa Luzia.

Outro dado sobre o assunto que chama bastante atenção é o já citado grande número de brasileiros a percorrer o Caminho de Santiago, na Espanha. Scgundo a Associação dos Amigos do Caminho de Santiago do Brasil, com sede em São Paulo, o número de credenciais (documento que identifica o peregrino) emitidas $\mathrm{cm} 1999$ passou de 2 mil. Porém grande partc dos brasileiros desconhece a existência da associação em São Paulo c retiram suas credenciais apenas $\mathrm{cm}$ solo europeu. Com isso o número de peregrinos brasileiros que percorreram o Caminho de Santiago no ano em questão provavelmente supcrou a marca dos 3 mil. Estatísticas da província de Burgos apontaram o Brasil como o terceiro país em número de peregrinos nos meses de junho e julho do mesmo ano. Deve-se ressaltar que a distância entre Brasil e Espanha e o relativo alto custo da viagem para o poder aquisitivo brasileiro são fatores altamente restritivos. Esses dados mostram o grande potencial do mercado brasileiro para este tipo de produto.

Nos moldes do caminho espanhol, está sendo desenvolvido no Espírito Santo o Caminho dos Passos de Anchieta. Esta rota, usualmente feita pelo beato entre Vitória e a vila de Iriritiba (atual cidade de Anchieta), possui cerca de $100 \mathrm{~km}$ e pode ser percorrida $\mathrm{em}$ três dias. São realizadas anualmente caminhadas programadas para a promoção do caminho e cm 1998 foram reunidos 200 peregrinos. Em 1999 o número de pessoas já ultrapassou 1.500 pessoas. Toda organização é feita pcla Assocıação Brasileira dos Amigos dos Passos de Anchieta(ABAPA). A intenção da associação é promover a instalação de infra-estrutura adequada, para que em pouco tempo os peregrinos possam percorrer a rota durante todo o ano, não dependendo 
apenas da caminhada programada (Hasse, 1999).

\section{Consideraçōes Finais}

A atual situação das peregrinações como fenômeno é paradoxal. Apesar de sua imensa importância histórica e seu enorme potencial, esta se encontra muito) distante ter a merecida atenção governamental e privada.

No mundo existem poucas iniciativas de desenvolvimento da atividade. É o caso de Santiago de Compostela, por exemplo, que atingiu um alto grau de organização e popularidade através da ação governamental, com patrocínio de inúmeras empresas privadas, gerando muitos benefícios a população espanhola em geral.

No Brasil, a organização de peregrinações, como a da Aparecida, por exemplo, pode dar excelentes resultados para o governo, empresas e peregrinos. A participação de universidades e outras instituições também pode oferecer imensa ajuda.

Por fim, ressalta-se mais uma vez o grande potencial deste fenômeno como atividade turística, gerando emprego e renda, preservando a cultura e a história.

\section{Referências Bibliográficas}

APARECIDA. SÃO PAULO. Prefeitura Municipal. Apresenta site oficial da cidade. Disponível em: <http:// www.aparecida.com.br.> Acesso em agosto de 2000.

FUSTER, Luis Fernández. 1985. Introducción a la teoría y técnica del turismo. Madrid: Alianza Editorial.

HASSE, Geraldo. 1999. O andarilho do Brasil Colonial. D. O. Leitura, ano 17, n. 2, p. 14-25.

HERRERA, José Luis. 1984. Consideración turistica del Camino de Santiago. Estudios Turisticos, v. 84, p.17-30.

JARRET, Bede. 2000. The Catolic Encyclopedia. In: New Advent. Disponivel em: <http://www.newadvent.org.> Acesso em agosto de 2000

MACEDO, Toninho. 1999. Mapa cultural paulista. D. O. Leitura, ano 17, n. 6.

RIBEIRO, Ronaldo. 1997. Varanasi, vida e morte. Os caminhos da terra, ano 6, n. 9, p. 32-41, ed. 65.

ROMANINI, Vinícius. 1998. Meca de milhōes de fiéis. Os caminhos da terra, ano 7, n. 10, p. 52-57, ed. 78.

ROUSSEL, Romain. 1956. Les Pèlerinages. Paris: Presses Univerditaires de France. 